\title{
The History and Culture of Dolphinfish (Coryphaena hippurus) Exploitation in Japan, East Asia, and the Pacific
}

Hashimura Osamu, Tokyo Gakugei University, Faculty of Education, Japan

\section{Introduction}

What is the history behind human exploitation of dolphinfish (Coryphaena hippurus), and why were they so sought after by groups in the Pacific over such long periods of time (Figure 1)? The purpose of this paper is to examine the relationships between humans and dolphinfish, a highly migratory species that requires trolling technologies in order to catch.

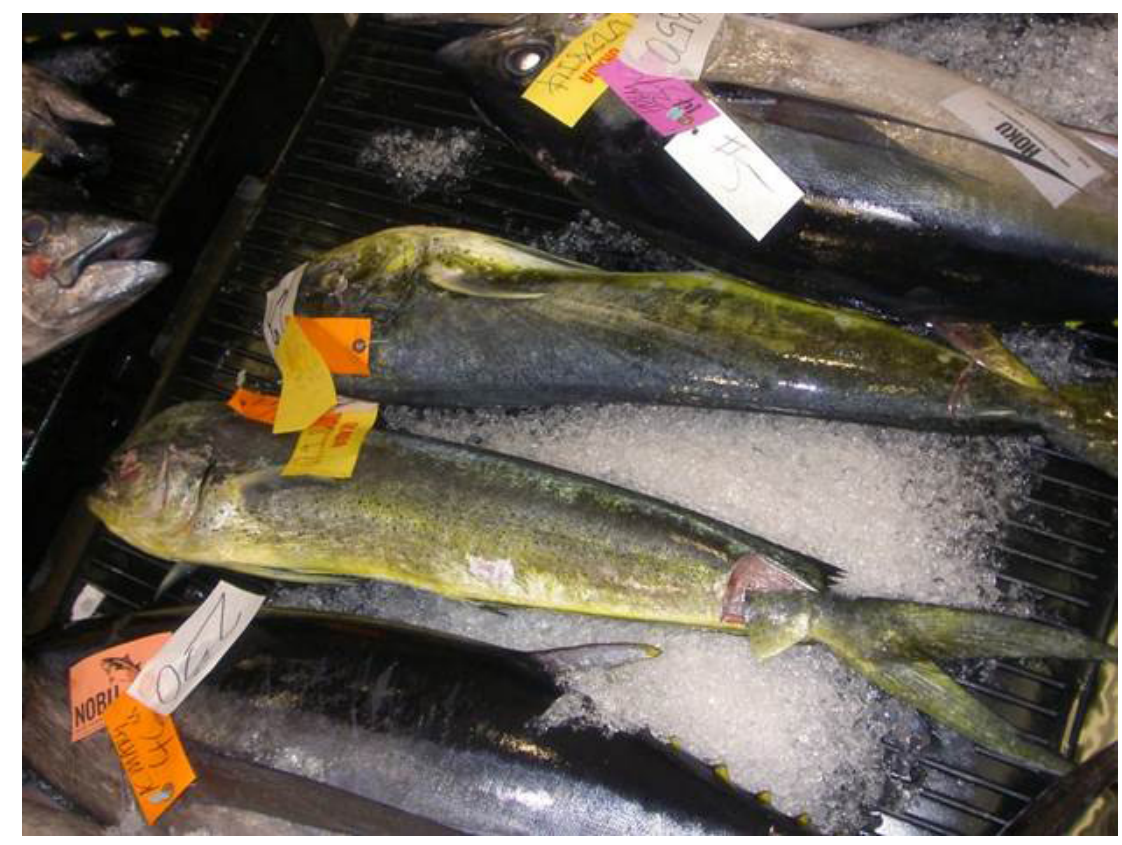

Figure 1. Dolphin fish (Coryphaena hippurus).

Source: Photo by the author. 


\section{Research Background}

The Japanese Archipelago is situated along the northwestern Pacific Rim, at the juncture where numerous species of migratory fish pass through nearby waters. In total, there are 350 species of endemic fish and two types of migratory fish. These include: 1) fish found in the warm Kuroshio Current, such as tuna, bonito, yellowtail, Spanish mackerel, sword fish, dolphinfish, and flying fish; and 2) fish found in the cold Oyashio Current, such as saury, herring, and salmon. In general, the warm water surface fish arrive from the south, while the colder water fish arrive from the north.

Dolphinfish (Coryphaenidae) consist of two subspecies in Japan: Coryphaena hippurus and $C$. equiselis. They originate in the Pacific, are found widely in tropical and sub-tropical seas, and reach approximately $0.5 \mathrm{~m}$ to $2 \mathrm{~m}$ in length. Dolphinfish migrate in groups from May to December and move northward (agari shiira) in waters around Japan during the summer season, moving south (modori shiira) again after late summer.

Dolphinfish are an extremely valuable resource for small-scale fisheries and are popular among recreational fishers in Japan. Both species are often exploited by taking advantage of behaviour aggregates under floating devices (Scientia Marina 1999), behaviour also found in other fish species, especially in their juvenile stage. However, dolphinfish have less value economically than tuna, bonito, and herring in Japan and, as such, are not as frequently caught. Their value, however, is different depending on locality. Consumers in Japan, for example, especially in urban areas, tend to prefer tuna, bonito, and sea bream over other species, though dolphinfish catches in Japan have been increasing in recent years.

Because dolphinfish are known to have been an important resource in Japan and East Asia, as well as in the Pacific Islands and South America prehistorically, and given the paucity of information known about their species, I review and discuss two major aspects of research: 1) the regional distribution of the tsuke method, one of the known FADs (Fish Aggregative Devices), and the cultural and historical use of dolphinfish in Japan; and 2) the relationship between dolphinfish and human societies in various regions from a view of comparative cultural and historical perspective.

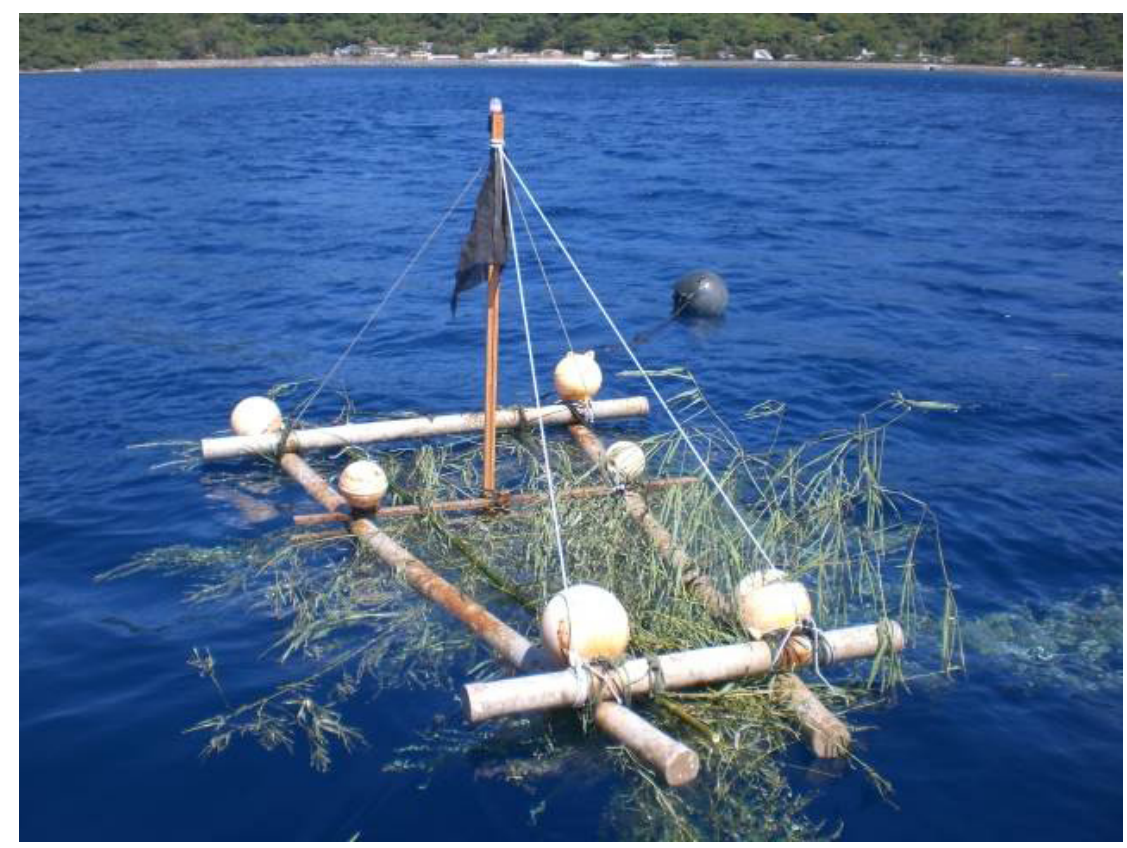

Figure 2. Bamboo rafts (tsukegi).

Source: Photo by the author. 


\section{Tsuke Fishing and Dolphinfish Exploitation in Modern Japan}

\section{Description of fishing methods}

In modern Japan, the capturing of dolphinfish is either done through net fishing with bamboo rafts (tsukegi) or angling/luring (Figure 2). The Japanese "shiira-zuke" (shiira=dolphinfish, $z u k e=t s u k e=$ float) fishing method mainly targets dolphinfish using a method that takes advantage of migratory fish behaviour, such as when skipjack (Katsuwonus pelamis) and yellowfin tuna (Thunnus albacares) congregate under floating objects like driftwood and floating seaweed. Fishermen set out bamboo rafts, called tsukegi ("floating wood" in Japanese), on the surface of the sea, and fish are then caught using a purse seine net. This type of fishing is considered a form of a fish aggregation device (FAD) (Kakuma 2000, 2002:39-59), which restricts the potential fishing grounds to relatively shallow waters over the continental shelf and areas devoid of strong currents.

In the Kochi District in Western Japan (Figure 3), for example, these rafts are situated 30-40 miles offshore in waters that normally do not exceed 1000 metres in depth. During the fishing season (June-November), more than 2000 tsukegi may be set over these areas. To avoid excessive competition for space, the setting line of respective tsukegi is decided by lottery every year. In principle, a vessel will only operate along their assigned line, unless there is agreed cooperation with other vessels.

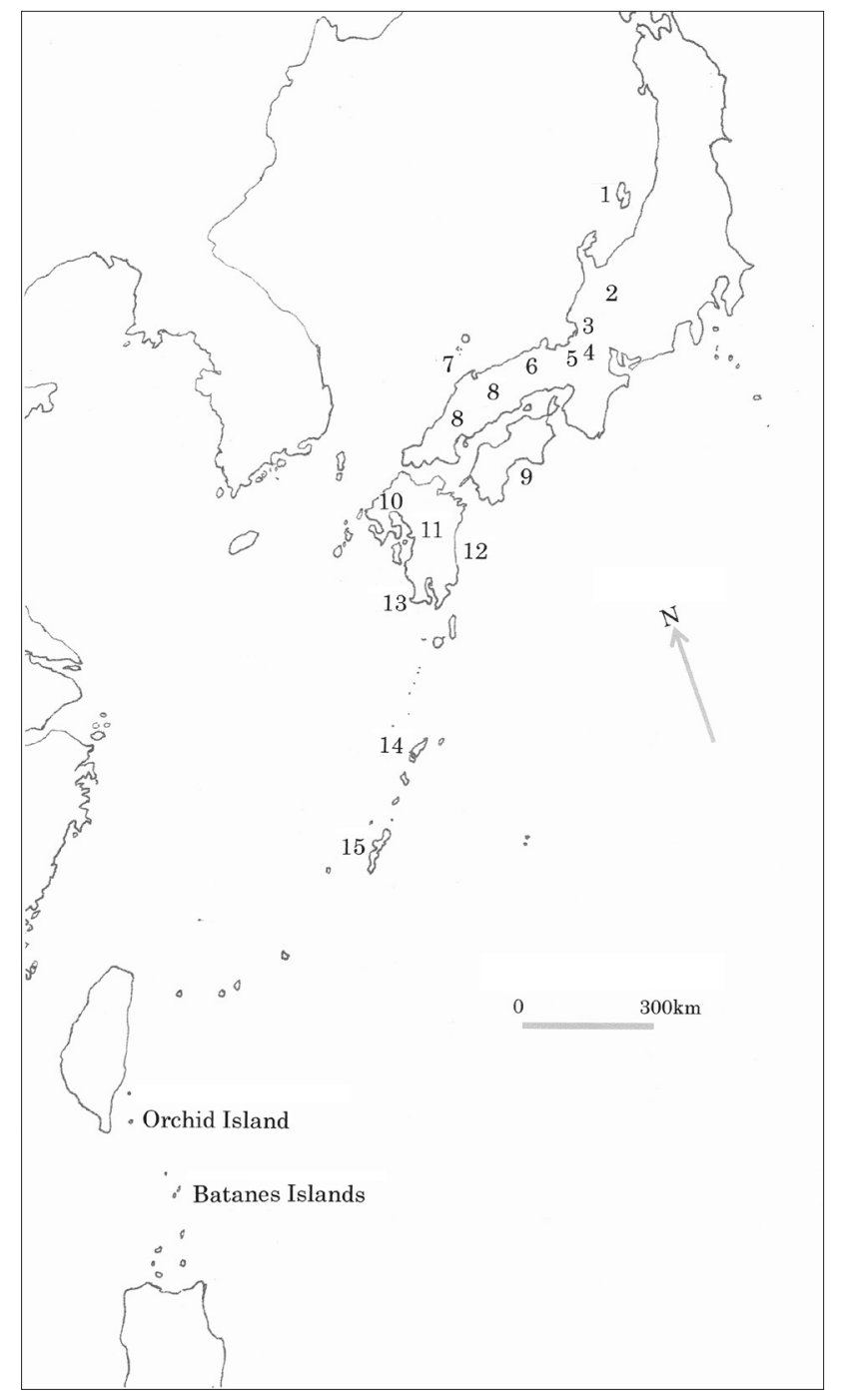

Figure 3. Major fishing grounds for Tsukegi fishing in Japan and Taiwan.

Source: Map by the author. 
Major fishing grounds for this type of fishing technique are widely distributed along the western coast facing the Sea of Japan (see Table 1 and Figure 3). The only exceptions are the districts of Kochi and Miyazaki, which face the Pacific coast. Although the shiira-zuke has traditionally been a fishing method that targets dolphinfish, in recent years the major catch by this method has been amberjack (Seriola lalandi) (Sakamoto and Kojima 1999:375-385).

Table 1. Regional distribution of dolphinfish consumption and festival use in Japan.

\begin{tabular}{|c|c|c|c|}
\hline No.* & Place Name & Host & Subject \\
\hline 1 & Niigata, Sado island & Fishing village & Festival in Aikawa \\
\hline 2 & Gihu, Hida & City & Seafood. salting fish \\
\hline 3 & Fukui, Mikata Tsunekami & Fishing village & New year festival \\
\hline \multirow[t]{2}{*}{4} & Shiga, Takashima Kutusuki & Farm village & New year festival \\
\hline & & & Harvest festival in autumn \\
\hline 5 & Kyoto & City & Harvest festival in autumn \\
\hline 6 & Totutori & Fishing village & New year festival \\
\hline 7 & Shimane, 0ki & Fishing village & Sushi seafood \\
\hline \multirow[t]{3}{*}{8} & Okayama. Hiroshima & Mountain village & New year festival \\
\hline & & & The festival of the Dead in summer \\
\hline & & & Harvest festival in autumn \\
\hline 9 & Kochi & Fishing village & First fishing festival of a year \\
\hline \multirow[t]{3}{*}{10} & Ngasaki. Saga & Fishing village. City & New year festival, called "Shargi" (happy tree). \\
\hline & & & "Okunchi" festival. \\
\hline & & & Harvest festival in autumn \\
\hline \multirow[t]{3}{*}{11} & Kumamoto & Mountain village. City & New year festival \\
\hline & & & The festival of the Dead in summer \\
\hline & & & Harvest festival in autumn \\
\hline 12 & Miyazaki & Fishing village & Promote the development of regional resources \\
\hline \multirow[t]{2}{*}{13} & Kagoshima & Fishing Village & Summer festival in 19thC \\
\hline & & & First fishing festival of a year \\
\hline \multirow[t]{2}{*}{14} & Kagoshima. Amami Island & Fishing village & New year festival \\
\hline & & & Harvest festival in autumn \\
\hline 15 & Okinawa. Main island & Fishing village & The year's first fishing display by fishermen. "ishinougan" \\
\hline
\end{tabular}

* Numbers above correspond to Figure 3 above.

Source: Table by the author.

Trolling and longline fishing have also been popular along the eastern coast facing the Pacific. For trolling, one- to five-metric-ton vessels use cut riggers to tow two main surface lines and several subsurface lines, each employing one to three hooks and artificial bait. These typically operate between June and August, about five to 30 miles from shore. The longline fishery uses larger three- to 10-metric-ton vessels, which deploy $10-16 \mathrm{~km}$ of multi-hook, subsurface (9-12m depth) longlines. These vessels usually operate between five and 30 miles from shore between May and July (Sakamoto and Kojima 1999:375-385). 


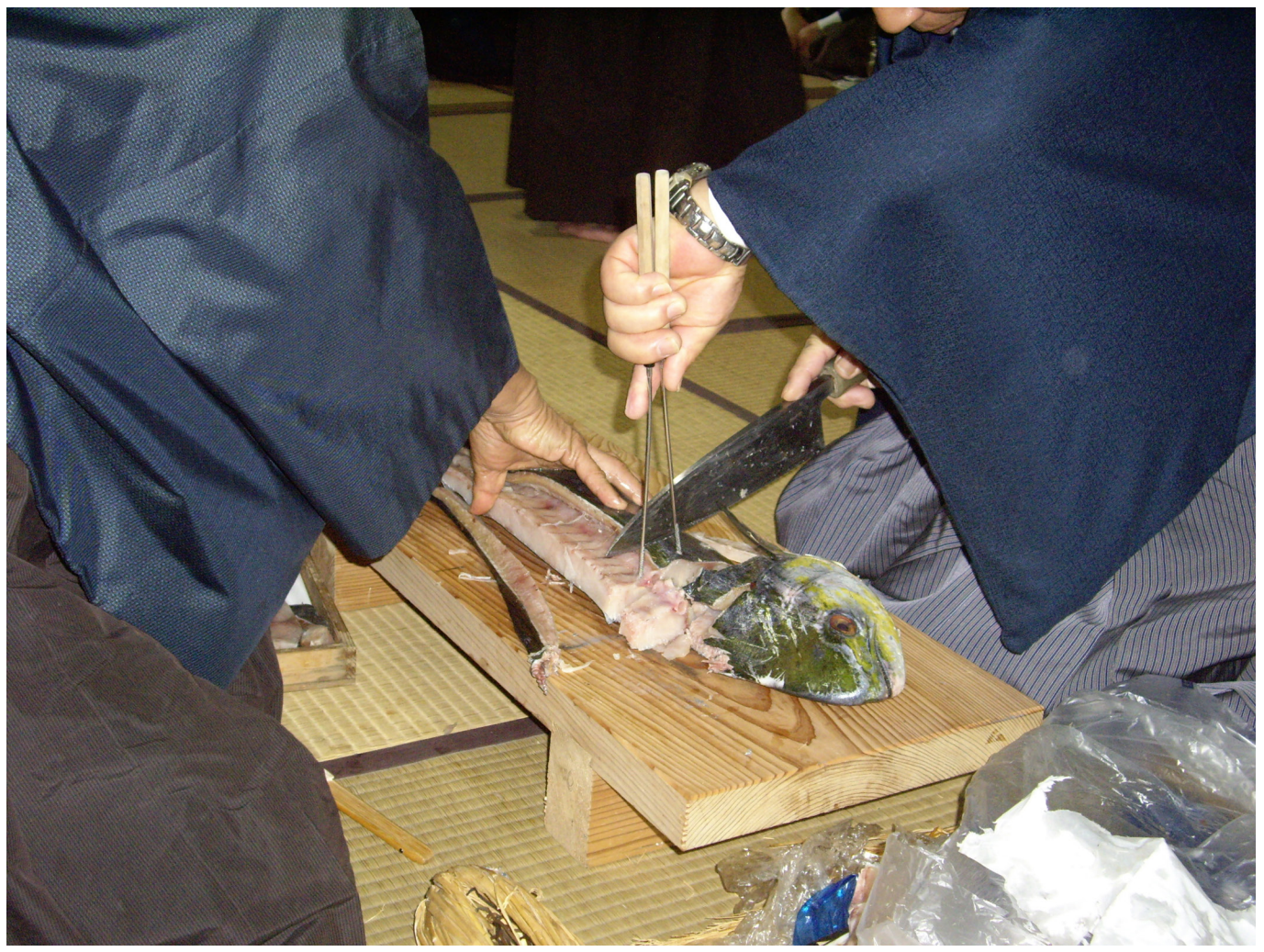

Figure 4. The cutting ceremony in Kutsuki, Takashima City, Shiga Prefecture.

Source: Photo taken by the author.

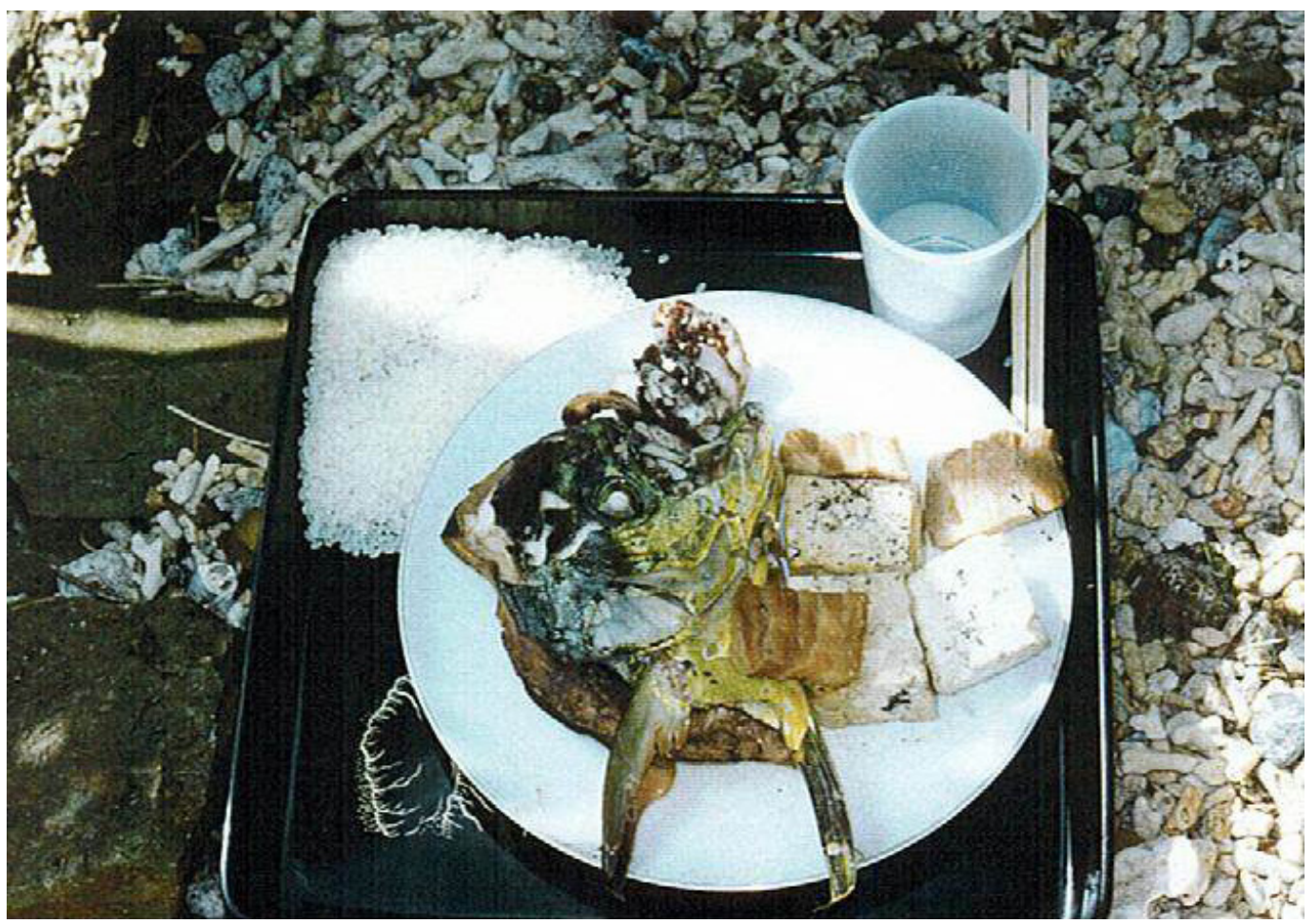

Figure 5. Narezushi in Ginama Village, Okinawa.

Source: Photo taken by the author. 


\section{Human consumption patterns of dolphinfish in Japan}

Daily use as food

Currently, dolphinfish are used primarily in fresh sashimi in areas where they are actively caught. However, because the flesh spoils relatively quickly, the fish is often sold as fillets in many urban supermarkets. They are typically deep-fried, served a la meuniére, or boiled slowly in a soy broth. There are many areas, such as Ibusuki, Kagoshima Prefecture, where dolphinfish and flying fish are minced as raw materials for Satsuma-age or Kamaboko. Once sold as a fillet or minced, however, consumers no longer know exactly what fish they are consuming. In the mountain regions, migratory fish are widely used. It is known that whales, dolphins, and sharks are delivered to and eaten in the mountain regions of northeast Japan to Kyushu.

\section{Traditional ritual use}

In terms of traditional uses, there are many rituals related to dolphinfish exploitation in Japan. For example, the ritual cutting of dolphinfish, using chopsticks and knives during the New Year's celebration, is widely preserved in the districts of Kinki (e.g., Shiga, Kyoto), Hokuriku (Fukui), the mountainous areas of Chugoku (Tottori, Shimane, Hiroshima), Kyushu districts (Miyazaki, Kumamoto, Nagasaki, Kagoshima), and in the Ryukyu Islands of Amami and Okinawa (see Table 1 and Figure 3 above). In Aso, Kutsuki, Takashima City, and Shiga Prefecture, a dolphinfish is offered to a community god first before the cutting ceremony is conducted, using a knife and chopsticks on New Year's Day (Figure 4). For example, dolphinfish or shark meat are usually recognised as a special fish for New Year's events among mountain villages in the Chugoku District of western Japan. Along the Gonokawa River in Shimane Prefecture, the dolphinfish is called mansaku and is usually eaten on the west side of the river, while the shark, called wani, is eaten on the east side. In Chizu town in Tottori Prefecture, the dolphinfish is commonly eaten as narezushi (fermented fish with rice) during New Year's.

People have also used the dolphinfish as one of the special foods for various rituals relating to life ceremonies, autumn harvest festivals, and other annual events. In these cases, narezushi is usually consumed. In Ginama Village in Okinawa, September 1 in the lunar calendar is regarded as the beginning of the fishing season and so-called "Ishinou-gan". During these times, a prayer for inviting dolphinfish is accompanied by serving the boiled fish to participants (Figure 5).

The reasons why the dolphinfish appears in traditional rituals in Japan might be related to the ease with which its meat can be preserved using salt, and to its size, which seems to represent good luck and fortune. However, the introduction and expansion of the use of electric refrigeration after World War II drastically reduced such customs, while dramatically increasing the importance of raw fish (tuna and other fishes) for sashimi and sushi. This eventually led to the decline of traditional food culture surrounding fish consumption.

\section{Historical Transition of the Dolphinfish Exploitation in Japan}

\section{Before Tokugawa Period (before AD 1603)}

In Japan, there have traditionally been two types of fisheries: one subsistence-based and the other revolving around commercial or industrial use. As noted in the archaeological record, fishing for subsistence has been a prominent feature throughout Japan's prehistory since the Jomon Period (ca. 13,000 to $2500 \mathrm{BP}$ ) and perhaps even earlier, during the Palaeolithic. Presently, the earliest traces of dolphinfish exploitation date back to the early Jomon Period around 11,000 BP. At the Torihama shell midden site in Fukui Prefecture, which dates back to 11,180 \pm 180 BP, dolphinfish bones were excavated together with yellowtail, black sea bream, porcupine fish, skipjack tuna, 
shark, forktail, bullhead, sea bass, and Japanese Spanish mackerel (Research group of Torihama Kaizuka 1987). At the San-nai Maruyama site in Aomori Prefecture, dolphinfish bones were also excavated from layers corresponding to the mid-late Jomon Period between 6,000 and 5,000 BP (Fukuda 2006:1-16). There are also traces of dolphinfish exploitation at the Nishinoshou site, which is estimated to be the production site for salt-making earthenware during the 5th century in Wakayama Prefecture (the Educational Board of Wakayama Prefecture 1997). Much later, dolphinfish bones were unearthed at the ruins of Nakijin Castle on Okinawa (Ryukyu Islands), dating back to the 13th century (Okinawa Prefecture, Nakijin Village Educational Committee 2009:179-238).

\section{The Tokugawa Period (AD 1603-1862)}

Today, dolphinfish are generally treated as low-grade fish in Japan. However, historical documents from the late Muromachi Era to the Tokugawa Period and Meiji Era (the 15th to 19th centuries), indicate that dolphinfish were treated as higher-grade fish than various tuna species (including skipjack). The ease with which the fish could be salted or smoked might be one reason why this particular fish species was deemed more important, considering the fact that the electric refrigerator had not yet been invented.

During the Tokugawa (or Edo) Period, rapid technological advancements in commercial fisheries led to changes in the kinds of species that were harvested and how they were procured. In the Wakasa region (Fukui Prefecture) around the 16th century, for example, dolphinfish were treated as more expensive than Tai (red snapper/Pagrus major) (Hashimura 2003:199-223). At this time, local fishermen caught them by using floating FADs such as tsukegi, which were made of bamboo. It was during the Meiji and Taisho Periods that seine pursing began.

Among the Goto Islands in Nagasaki Prefecture (Kyusyu District), local fishermen also captured dolphinfish, one of the primary species caught, along with whale and tuna, from the 17th to the 19th centuries (Hashimura 2009a:30-85). The main method for capturing dolphinfish was netting. For example, during the end of the 18th century in Kisyuku Village on Fukue Island, dolphinfish and tuna were usually caught by using a fixed net. Tuna were then pickled in sake, while some were exported from Goto to Osaka and other parts of Kyushu. Salted dolphinfish were also distributed to northern Kyushu as food during the festival of Okunchi.

Despite the prolific existence of fixed-net tuna fishing, as well as whaling, the question remains as to why dolphinfish have been continually caught. In part, I believe that it may be due to their role in long-term sustainable fishing practices throughout the Japanese archipelago. The targeting of species such as dolphinfish, while often small in terms of catch size, nevertheless provided a stable and relatively easy way to capture a reliable food source. On the other hand, fishing for larger migratory fish, such as tuna and whales, was sometimes very dangerous and presented a higher risk of coming back empty-handed.

\section{The Meiji and Taisho Periods (AD 1850-1920)}

In the Kyushu and Chugoku regions, the treatment of dolphinfish varied between mountain villages and fishing villages, and even towns and urban areas in the same region (Hashimura 2003:199-223). Historical documents at this time also refer to large quantities of dolphinfish being harvested in Shimane and Nagasaki Prefectures (Hashimura 2005:273-291) as well as in Okinawa.

With regard to fishing methods and technology, the seine FAD known as tsukegi began sometime between the Meiji and Taisho Periods among Kochi, Miyazaki, Kumamoto, Nagasaki, Shimane and Ishikawa Prefectures. As such, it is clear that the tsukegi method for capturing dolphinfish had expanded to the Pacific coast of Japan during this time. 


\section{The Showa and Heisei Periods (AD 1920 to present)}

In the early Showa Period prior to World War II, the increased popularity of the refrigerator quickly diminished the importance of salting dolphinfish, which subsequently began to be perceived as a "trash fish". In terms of fishing technology and potential fishing grounds, during the post-war Showa Period up to the Heisei Period, people began to focus on areas farther from shore. This was made possible by the development of a large floating fish reef known as a payao. An FAD fishing method originally developed in the Philippines and Indonesian seas, the outcome was that fishing areas were extended to the coasts of the Ryukyu Islands from Meiji from the 1920s through to 1982. Although payao increased the offshore catch of tunas and dolphinfish, it also led to several problems. According to fishermen on Okinawa and Miyazaki, for example, while the migratory fish caught off the coast had increased with the establishment of payao, the number of migratory fish caught by net fishing in coastal areas has declined (Kakuma 2002:39-59).

\section{Regional Differences in the Dolphinfish and Fish Food Distribution System}

\section{Distribution of name}

Apart from archaeological and historical evidence, it is important to examine the linguistic evidence regarding the species to provide a more robust interpretation of dolphinfish exploitation over time. Here, I compare the dialectic distribution of the dolphinfish's name.

The dolphinfish was important in the East China Sea. In this area, names given to dolphinfish are generally positive in nature; for example: hiiwo, fu-nyuiyu, hii, manbiki, and manriki. Fu-nyuiyu is a local name for the dorado in Okinawa. $F u$ refers to wealth in the local Okinawan dialect, and iyu means "fish". Hii is the local name for the dorado on Amami Island. Manbiki is the local name for the dorado in the southern part of Kyushu and the southern part of Shikoku. Hiiwo is the local name for the dorado in western Kyushu.

In contrast, along coastal areas of the Sea of Japan, such as the Kanto region, it is hated. Consequently, negative terms are used; for example, Siira (empty rice husk), and Shibitokurai (fish that eats corpses). From an areal study of the dolphinfish names mentioned above, I next examine the differences in how dolphinfish are valued between the Japanese and East China Seas. As I suggest, altering perceptions of how dolphinfish are valued derives from a decline in catches at the level of local economies.

\section{Dolphinfish exploitation in the China Sea}

In Korea, dolphinfish are known as manzegi or pusiri. On Chin-do Island, salted dolphinfish used to be served on New Year's Day and Obon (mid-summer) festivals until as recently as 50 years ago. On Ranyu (Orchid) Island in Taiwan, a type of dolphinfish called arayu is the most valuable fish. People initially catch flying fish called aribaban as the bait for dolphinfish (Yamada 1967). In China, consumption of dolphinfish was common in the areas dominated by Westerners in Hong Kong, indicating a preference by certain groups for eating this particular fish. Along other coastal locations of China, dolphinfish fishing is not popular since the fishing grounds are remotely located, though today, when captured, they are typically ground up into meal. 


\section{Dolphinfish exploitation in Hawai i}

In Hawai' $i$, the dolphinfish is known as mahimahi, similar to other parts of Polynesia, and is popular among tourists today. Although dolphinfish has been exploited since prehistoric times, it was not considered a desirable fish to Native Hawaiians. It was only during the 1960s that mahimahi was recognised as the state fish (Takenaka 1984:1-20), after tourists became increasingly fond of the species for game fishing. Throughout the 1960s and 1970s, the import of frozen dolphinfish by several Asian countries—namely Taiwan, Japan, and Vietnam-began. In 1989, Costa Rica and Ecuador began exporting fresh dolphinfish to the U.S. and other locations, with Hawai'i becoming the centre for its distribution.

\section{Dolphinfish use in Costa Rica}

In Costa Rica, the consumption of terrestrial animals has been a central part of traditional subsistence, so the fishing industry has not been as popular (Hashimura 2007:269-300). Prior to the 1980s, commercial harvesting was limited to small-scale shark fishing by the Taiwanese, while near-shore fishing remained minimal. Domestic consumption of dolphinfish in Costa Rica was extremely limited, in part because it was not well-liked by locals (Hashimura 2007:269-300); however, the situation changed, beginning in the early 1980s, due to an expansion of the global distribution of marine products. As a result, common dolphinfish and striped marlin fishing were initiated by the opening of export markets to the U.S. The commercial value of dolphinfish increased due to heightened demand, and the U.S. later became the lead importer of Costa Rican dolphinfish. This pattern also led to greater consumption of dolphinfish by local American tourists after an appointment by the Natural World Heritage committee helped increase the demand (Chant 1992: 85-101).

The continued growth of the Costa Rican dolphinfish industry and high levels of tourism have generally led to greater demand. To cope with this situation, the government of Costa Rica (INCOPESSCA: Institute Costarricense de Pesca y Acuicultura) has introduced strict management rules for marine resources, including a total ban on fishing around the area of national parks; a seasonal restriction on fishing is also being considered.

Overall, I have compared how the recent relationships between humans and dolphinfish differ in Costa Rica and various parts of Asia. In the western Pacific, especially in Japan, dolphinfish are categorised as a minor fish, unlike tuna, bonito, or sea bream, which are classified as high-grade fishes. In contrast, dolphinfish in Costa Rica is treated as a high-grade fish, primarily given its value to U.S. markets.

In addition, the philosophies behind properly managing these types of marine resources are very different between Asia and Costa Rica. In Japan and Taiwan, more emphasis is placed on using a FAD (Fish Attractant Device) than in setting area restrictions or seasonal bans on fishing. On the other hand, in Costa Rica, the use of an FAD is forbidden, whereas the seasonal and zonal prohibition of fishing is widely practiced (Hashimura 2007:269-300).

\section{Discussion and Conclusion}

In this paper, I have briefly discussed the history of dolphinfishing across parts of the Pacific. It is important, however, to point out some newly clarified matters and future tasks.

As noted previously, the antiquity of dolphinfish exploitation in Japan may date back to as early as 11,000 years ago. This early emphasis on the harvesting of dolphinfish can also be compared to consumption patterns found on neighboring islands in the Asia-Pacific region. For example, 
archaeological studies on Guam (see the chapter by Amesbury in this volume), Taiwan (e.g., Lee 1997), and the Philippines reveal that dolphinfish were also exploited in prehistory, though not as early.

Additionally, this paper demonstrates that there are distinct temporal changes in how dolphinfish were utilised in Japan from the 16th century to the present. Although dolphinfish today in Japan are economically categorised as low-grade and are relatively inexpensive, it is clear that they have served some very important functions historically, often presented to local lords by the villagers, offered to the gods, and, in some cases, served at wedding ceremonies. Such customs are also practiced in the southern districts of Korea, Taiwan, and probably in certain areas of East Asia. It would also be interesting to compare these activities with those seen in the Mediterranean (Jeanne and Hiechmi 1999:469-472) in future studies.

The next question remains as to why dolphinfish were auspicious during the Edo Period until the first half of the 20th century. In my opinion, the reason why dolphinfish became a cheap and low-class fish is possibly related to the development of preservation technology through the introduction of refrigerators (Hashimura 2003:199-223), by which the widespread distribution of tuna and bonito fish became possible while dolphinfish became comparatively tainted.

However, dolphinfish is very popular as a light fish, similar to tilapia and codfish. With the increased scarcity of marine products in modern Japan, there is a re-valuation movement of minor fish resources, such as dolphinfish, which are not mass-harvested like tuna has been over the past couple of centuries. Subsequently, there is now a revitalisation movement of depopulated communities. Such movement should be socially expanded through an understanding of the history of dolphinfish and their place in culture (Hashimura 2010:190-214). Through the analysis of relationships between fish and humans, we can observe historical preferences in fish consumption across space and time, noting how and why specific variables have come into play to structure subsistence patterns.

\section{References}

Chant, S. 1992. Tourism in Latin America: Perspective from Mexico and Costa Rica. In D. Harrison (ed), Tourism and the Less Developed Countries, pp. 85-101. London: Belhaven Press.

Fukuda, T. 2006. The archaeological sites with shell remains in northern area of HONSHU Island, Japan. In Aomori Prefectural Museum (ed), Proceedings of the Aomori Prefectural Museum 31, pp. 1-16. Aomori: Prefectural Museum (in Japanese).

Hashimura, O. 2003. Regional Differences and History in the Use of Dolphinfish (Coryphaena hippurus Linne): The Case Study of Warm Current of Tsushima. Senri Ethnological Reports 46:199223. (in Japanese).

Hashimura, O. 2005. Regional Differences of the fishery and the Use of Dolphinfish (Coryphaena hippurus Linne) in Japan Archipelago: The Case Study of Meiji era. Kokugakuin University Archeology Museum Bulletin 21: 273-291. (in Japanese).

Hashimura, O. 2007. Fishing, distribution, culture of dorado resource in countries of the Pacific rim especially of Hawaii, Costa Rica. In N. Kishigami (ed), Indigenous Distribution and Management of Marine Resources, pp. 269 -300. Suita: National Museum of Ethnology, Japan. (in Japanese).

Hashimura, O. 2009a. Social history of marine tenure during the Tokugawa period in Japan. Kyoto: Jinbunsyoin. (in Japanese).

Hashimura, O. 2009b. The folklore of migrate fishes in Okinawa, Amami Island. Nampo-bunka 36. (in Japanese). 
Hashimura, O. 2010. The Ecological history of the use of Migratory fish resources in Japan Sea. In Kazunobu Ikeya (ed), Wildlife-Human Relationships in Japan, pp. 190-214. Tokyo: Sekaishisosha. (in Japanese).

Jeanne, Z. and M. Hiechmi. 1999. Small-scale Tunisian fishery for dolphinfish. Scientia Marina 63(34):469-472.

Kakuma, S. 2000. Current, catch and weight composition of yellow-fin tuna with FADs off Okinawa Island, Japan. In J.-Y. Le Gall, P. Cayré, and M. Taquet (eds.), Pêche thonière et dispoitifs de concentration de poisons, pp. 492-501. Plouzané: Ifremer.

Kakuma, S. 2002. The evolution and conflict of Payao fishery in Okinawa. In T. Akimichi and N. Kishigami (eds), Conflict of maritime use, pp. 39-59. Tokyo: Jinbunsyoin. (in Japanese).

Kraul, S. 1999. Seasonal abundance of the dolphinfish, Coryphaena hippurus. Scientica Marina 63(34):261-266.

Okinawa Prefecture Nakijin Village Educational Committee (ed). 2009. Archaeological Report of Nakijin Gusuku Excavation. Okinawa: Okinawa Prefecture Nakijin Village Educational Committee. (in Japanese).

Olson, R.J. and F. Galván-Magaña. 2002. Food habits and consumption rates of common dolphinfish in the eastern Pacific Ocean - Coryphaena hippurus. Fishery Bulletin 100(2):279-282.

Research group of Torihama Kaizuka (ed). 1987. Torihama Kaizuka. Fukui: Fukui Prefecture. (in Japanese).

Sakamoto, R. and S. Kojima. 1999. Review of dolphinfish biological and fishing data in Japanese waters SCIENTIA MARINA 63(3-4):375-385.

Takenaka, B. and L. Torricer. 1984. Trends in the Market for mahimahi and ono in Hawaii. Southwest Fisheries Center Administrative Report 84-9:1-20.

Wakayama Prefectural Archaeological Center 1997. Annual report of Wakayama Prefectural Archaeological Center 1997. Wakayama: Wakayama Prefectural Archaeological Center. (in Japanese).

Yamada, Y. 1967. Fishing Economy of the Itbayat, Batanes, Philippines with Special Reference to its Vocabulary. Asian Studies 5(1):137-219. 